\title{
Amplification of mecA gene in multi-drug resistant Staphylococcus aureus strains from hospital personnel
}

\author{
Asad U Khan, ${ }^{1}$ Ayesha Sultan, ${ }^{1}$ Anju Tyagi, ${ }^{2}$ Shazia Zahoor, ${ }^{3}$ Mohd Akram, ${ }^{1}$ \\ Sukhminderjit Kaur, ${ }^{3}$ Mohd Shahid, ${ }^{2}$ Chetana V Vaishnavi ${ }^{1}$ \\ ${ }^{1}$ Interdisciplinary Biotechnology Unit, Aligarh Muslim University Aligarh 202002 India; ${ }^{2}$ Microbiology Department JNMC, AMU, \\ Aligarh, India; ${ }^{3}$ Gastroenterology Department, PGIMER, Chandigarh, India.
}

\begin{abstract}
Background: Antibiotic resistance is common among bacterial pathogens associated with both community acquired and nosocomial infections. In view of the present problem of drug resistance we investigated the prevalence of methicillin resistant Staphylococcus aureus (MRSA) and amplified the mecA gene in the isolates from the hand swabs of the hospital personnel.

Methodology: The nuc gene was amplified to characterize these isolates at species level. The $S$. aureus isolates were analyzed for their susceptibility to different classes of antibiotics using the disk diffusion method. The spot inoculation test was performed to detect methicillinase production in these isolates.

Results: In the screened isolates of $S$. aureus, 14.2 and $15 \mathrm{~kb}$ of plasmids were present. These isolates showed pronounced resistance against $\beta$-lactam antibiotics including second- and third-generation cephalosporins, aminoglycosides, macrolides and fluoroquinolone. Some of the isolates included in this study were resistant to three or more antibiotics. Expression of methicillinase was detected by spot inoculation test, and a few of the isolates were found to produce methicillinase. Moreover, $m e c A$ gene was also amplified. Of 17 isolates only 7 showed presence of mecA gene.

Conclusion: This study highlights the emerging trend of multiple drug resistance in $S$. aureus strains isolated from hospital personnel working in a premier hospital in North India.

Key Words: methicillin resistance, Staphylococcus aureus, plasmid, mecA gene, hospital personnel.
\end{abstract}

J Infect Developing Countries 2007; 1(3):289-295.

Received 4 October 2007 - Accepted 16 November 2007.

Copyright (C) 2007 Khan et al. This is an open access article distributed under the Creative Commons Attribution License, which permits unrestricted use, distribution, and reproduction in any medium, provided the original work is properly cited.

\section{Introduction}

Antimicrobial resistance is steadily rising among bacterial pathogens associated with both community and health care-associated infections $[1,2]$. Among the most important of these pathogens are vancomycin-resistant enterococci (VRE) and methicillin-resistant Staphylococcus aureus (MRSA) [3]. The majority of MRSA strains have been associated with hospital-acquired colonization and infections [4]. MRSA strains in nursing homes and long-term care facilities are usually of nosocomial origin [5], and most MRSA strains isolated from patients upon admission to hospitals or nursing homes can be traced to a previous stay in a similar setting [6]. In the mid1990s, however, infections with MRSA began occurring in communities in patients who had no history of previous hospital stays and known risk factors for acquisition of MRSA infection [7]. These MRSA isolates are referred to as community
MRSA (cMRSA) and have been reported from many parts of the world, including Canada [8], the United States of America, [7,9], Australia, the Southwest Pacific [10], and different European countries [11].

Risk for colonization or infection with $S$. aureus is highest in patients with diabetes mellitus, intravenous drug users, and patients undergoing hemodialysis, surgical patients, and patients with acquired immunodeficiency syndrome [12]. In the last few years, however, reports of patients with serious MRSA infections who had no known risk factors or exposure to a health care setting have been increasing [13-19]. The distinctive properties of the community acquired MRSA strain compared to nosocomial strains include a much more susceptible antimicrobial phenotype because of the presence of a much smaller staphylococcus cassette chromosome mecA (type IV) [20] and the 
presence of different exotoxin gene profiles, including Panton-Valentine leukocidin [6,11].

In view of the background outlined above, we initiated our investigations to study the resistance pattern of $S$. aureus strains isolated from health workers in a hospital environment. Moreover, we intended to characterize MRSA strains among these isolates by amplifying mecA gene and methicillinase assay.

\section{Materials and Methods}

Sample collection

Seventeen $S$. aureus isolates were obtained from hand-swab samples of thirty-four hospital personnel (doctors, nurses and ward boys) of the general ward of in-patients at the Post Graduate Institute of Medical Education and Research, Chandigarh, India.

Identification and molecular characterization of $S$. aureus

The isolates were identified as $S$. aureus morphologically on culture, by Gram staining and by using traditional biochemical tests, including catalase, coagulase, slide agglutination and phosphatase test [21].

Acid production was also detected from glucose, D-maltose, D-trehalose, D-mannitol, sucrose and $\beta$-D-fructose. Species identification was confirmed by polymerase chain reaction (PCR) amplification of thermostable nuclease gene (nuc) using the primers, nuc- $F$ (5'GCGATTGATGGTGATACGGTT-3') and nuc-R (5'-AGCCAAGCCTTGACGAACTAAAGC-3') as described by Brakstad et al. (22).

PCR conditions for nuc gene comprised a thermal temperature to $9^{\circ} \mathrm{C}$ for 5 minutes, followed by 34 cycles of $94^{\circ} \mathrm{C}$ for 1 minute, annealing at $55^{\circ} \mathrm{C}$ for 1 minute, and extension at $7^{\circ} \mathrm{C}$ for 1 minute, followed by final extension for 10 minutes at $72^{\circ} \mathrm{C}$.

\section{Antibiotic susceptibility testing}

Antimicrobial resistance of the isolates was determined by the disk diffusion method. The following antimicrobial agents at the indicated concentrations were tested: amikacin $30 \mu \mathrm{g} / \mathrm{ml}$; ceftriaxone $30 \mu \mathrm{g} / \mathrm{ml}$; ciprofloxacin $10 \mu \mathrm{g} / \mathrm{ml}$; gentamicin $10 \mu \mathrm{g} / \mathrm{ml}$; tobramycin $30 \mu \mathrm{g} / \mathrm{ml}$, amoxycillin $30 \mu \mathrm{g} / \mathrm{ml}$, methicillin $5 \mu \mathrm{g} / \mathrm{ml}$, oxacillin 1 $\mu \mathrm{g} / \mathrm{ml}$, penicillin $\mathrm{G} 10 \mu \mathrm{g} / \mathrm{ml}$, kanamycin $30 \mu \mathrm{g} / \mathrm{ml}$, cefoxitin $30 \mu \mathrm{g} / \mathrm{ml}$, cefotaxime $30 \mu \mathrm{g} / \mathrm{ml}$, doxycyclin $30 \mu \mathrm{g} / \mathrm{ml}$, erythromycin $10 \mu \mathrm{g} / \mathrm{ml}$, chloramphenicol $30 \mu \mathrm{g} / \mathrm{ml}$. Throughout this study, results were interpreted according to the criteria of the Clinical Laboratory Standards Institute [23].

\section{Determination of minimum inhibitory concentration (MIC)}

The four strains of $S$. aureus were inoculated into Brain Heart Infusion (BHI) broth in test tubes and grown to stationary phase for 24 hours at $37^{\circ} \mathrm{C}$ up to $108-109 \mathrm{CFU} / \mathrm{ml}$. $50 \mu \mathrm{l}$ of overnight growth culture diluted to 105-106 CFU/ml was inoculated into fresh $\mathrm{BHI}(50 \mu \mathrm{l})$ containing varying concentrations, serially diluted (512- $2 \mu \mathrm{g} / \mathrm{ml})$ antibiotics listed in Table 1.

Table 1. MIC of some selected antibiotics against MRSA strains, MIC $(\mu \mathrm{g} / \mathrm{ml})$.

\begin{tabular}{ccccccc}
\hline $\begin{array}{c}\text { MRSA } \\
\text { Strains }\end{array}$ & $\mathbf{M}$ & $\mathbf{P}$ & $\mathbf{O x}$ & $\mathbf{C i}$ & $\mathbf{C e}$ & $\mathbf{T b}$ \\
\hline $\mathrm{S} 13$ & 8 & 64 & - & - & - & $>16$ \\
$\mathrm{~S} 14$ & 16 & $>64$ & 32 & 16 & - & - \\
$\mathrm{S} 19$ & $>32$ & - & 32 & $>16$ & 8 & - \\
$\mathrm{S} 20$ & 16 & 16 & 64 & $>32$ & 16 & 64
\end{tabular}

Methicillin $(\mathrm{M})$, Oxacillin $(\mathrm{Ox})$, Penicillin G $(\mathrm{P})$, Tobramycin $(\mathrm{Tb})$, Ceftriaxone $(\mathrm{Ci})$, Cephotaxime (Ce). - .indicates not detected.

\section{DNA purification and PCR methods}

Plasmid DNA was prepared using the methods described by Birnboim and Doly, [24] and IshHorowicz and Burke, [25] and genomic DNA by the method described by Boom et al. [26]. PCR amplification of mecA gene was performed on 0.5 $\mu \mathrm{g}$ of genomic DNA as described earlier [27]. Primers for the detection of mecA were 5'AGTTGTAGTTGTCGGGTTT-3' and 5'AGTGGAACGAAGGTATCATC-3'.

PCR conditions for mecA comprised a thermal temperature of $9^{\circ} \mathrm{C}$ for 5 minutes, followed by 34 cycles of $9^{\circ} \mathrm{C}$ for 1 minute, annealing at $54^{\circ} \mathrm{C}$ for 1.5 minutes, and extension at $72^{\circ} \mathrm{C}$ for 1 minute, followed by a final extension for 10 minutes at $72^{\circ} \mathrm{C}$.

Spot inoculation test to detect methicillinase production in S.aureus isolates

The lawn culture of $S$. aureus Oxford (ATCC 29013) strain, which is sensitive to oxacillin, was prepared on Mueller-Hinton agar plates by 
swabbing the plates with bacterial culture corresponding to $0.5 \mathrm{McF}$ arland units.

This was left to dry for 10 minutes followed by division of the plate into four sections. An oxacillin disc $(1 \mu \mathrm{g})$ was placed in each section by means of a sterile blunt needle, and 4-5 colonies of each isolate were picked with the help of a sterile wire loop and placed as spots around each disc at a distance of 7-8 $\mathrm{mm}$.

Four isolates were spotted per disc. The plates were incubated overnight at $370 \mathrm{C}$ as described earlier [28].

\section{Results}

Identification and characterization of Staphylococcus aureus

The $S$. aureus isolates were first identified by morphological and biochemical characteristics. These strains were further characterized by amplifying thermostable nuclease (nuc) gene using the primers defined in the methodology section for characterization and confirmation up to the species level (Figure 1).

\section{Antibiotic susceptibility testing}

Of 17 isolates, methicillin resistance was shown by four (SA 13, SA 14, SA 19 and SA 20). SA 6 was the only isolate susceptible to all the antibiotics (Table 2).

Table 2. Antibiotic susceptibility and resistance pattern of different strains of $S$. aureus.

\begin{tabular}{|c|c|c|}
\hline $\begin{array}{l}\text { S. aureus } \\
\text { strains }\end{array}$ & $\begin{array}{l}\text { Types of antibiotic(s) } \\
\text { against which each strain } \\
\text { is resistant }{ }^{\#}\end{array}$ & $\begin{array}{l}\text { Strains of types } \\
\text { based on anti- } \\
\text { biogram }\end{array}$ \\
\hline$\overline{\text { SA } 1}$ & $\mathrm{Ci}$ & A \\
\hline SA 2 & $\mathrm{Ci}$ & $A$ \\
\hline SA 3 & $\mathrm{Ci}$ & $A$ \\
\hline SA 4 & $\mathrm{~Tb}, \mathrm{Ci}$ & $\mathrm{B}$ \\
\hline SA 5 & $\mathrm{Ci}$ & A \\
\hline SA 6 & None & C \\
\hline SA 7 & $E$ & $\mathrm{D}$ \\
\hline SA 8 & Am, D & $E$ \\
\hline SA 10 & $\mathrm{P}, \mathrm{Tb}, \mathrm{K}, \mathrm{G}$ & $\mathrm{F}$ \\
\hline SA 11 & $\mathrm{Ci}$ & A \\
\hline SA 12 & $\mathrm{Ox}, \mathrm{Tb}, \mathrm{Ci}$ & G \\
\hline SA 13 & $\mathrm{P}, \mathrm{T}, \mathrm{M}$ & $\mathrm{H}$ \\
\hline SA 14 & A, M, Ox, P, Ci, Do, & 1 \\
\hline SA 15 & $\mathrm{P}, \mathrm{Ci}$ & $\mathrm{H}$ \\
\hline SA 16 & $\mathrm{Ci}$ & A \\
\hline SA 19 & $\begin{array}{l}\mathrm{Am}, \mathrm{M}, \mathrm{Ox}, \mathrm{P}, \mathrm{G}, \mathrm{Tb}, \mathrm{K}, \\
\mathrm{Ci}, \mathrm{Ce}, \mathrm{D}, \mathrm{E}\end{array}$ & $\mathrm{J}$ \\
\hline SA 20 & $\begin{array}{l}\text { Am, M, Ox, P, G, Tb, K, } \\
\mathrm{Cn}, \mathrm{Ci}, \mathrm{Ce}, \mathrm{Do}, \mathrm{E}, \mathrm{Cf}\end{array}$ & $\mathrm{J}$ \\
\hline
\end{tabular}

All the isolates were susceptible to chloromphenicol and amikacin (Figure 1). Ciprofloxacin, the only fluoroquinolone used, was next in terms of efficacy, with only $6 \%$ of the isolates being resistant. Twelve percent of the isolates were found to be resistant to cefoxitin. In the cephalosporin group, most of the isolates were found to be sensitive to cefotaxime (only 6\% resistant) while ceftriaxone was the least effective among all the antibiotics used, as $80 \%$ of isolates were resistant to it. In the other $\beta$-lactam group, $18 \%$ of isolates exhibited resistance to methicillin, $24 \%$ to oxacillin and $40 \%$ to penicillin G. Intermediate resistance was found to erythromycin (Figure 2).

Figure 1. PCR amplification of nuc gene.

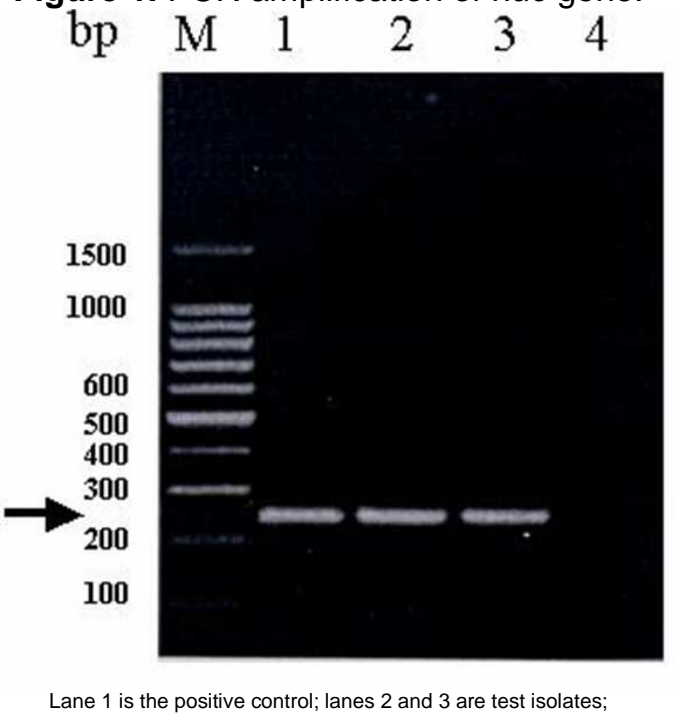

lane 4 is the negative control. $M$ is the $100 \mathrm{bp}$ marker.

Figure 2. The bar diagram explains the percent resistance against each antibiotic.

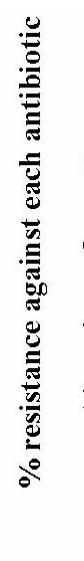

80
60
40
20
0

Abbreviations of the antibiotics are as follows: Amoxycillin (Am), Methicillin $\quad(M)$, Oxacillin $(\mathrm{Ox})$, Penicillin G (P), Amikacin (Ak), Gentamicin (G), Tobramycin (Tb), Kanamycin (K), Cephoxitin (Cn), Ceftriaxone (Ci), Cephotaxime (Ce), Doxycycline (Do), Erythromycin (E), Chloramphenicol (C), Ciprofloxacin (Cf).

Among the 9 isolates exhibiting multidrugresistance to the antibiotics used in this study, only 
three (SA20, SA19 and SA14) showed pronounced resistance against different classes of antibiotics such as $\beta$-lactams including secondand third-generation cephalosporins, aminoglycosides, macrolides and fluoroquinolone. SA20 was resistant to $86 \%$, while SA19 and SA14 were resistant to $73 \%$ and $40 \%$ antibiotics respectively (Table 2). Moreover, these strains were classified into 10 different types on the basis of antibiotic sensitivity profile (Table 2 ).

Minimum inhibitory concentration (MIC) was also determined for selected antibiotics among the four MRSA strains. The resistance data is provided in Table 1.

\section{Detection of mecA gene by PCR amplification}

The mecA gene is responsible for methicillin resistance in $S$. aureus. PCR amplification of mecA gene was positive in the following isolates: SA1, SA3, SA6, SA8, SA11, SA12, and SA20 (Figure 3).

Figure 3. PCR amplification of $\operatorname{mec} A$ gene.

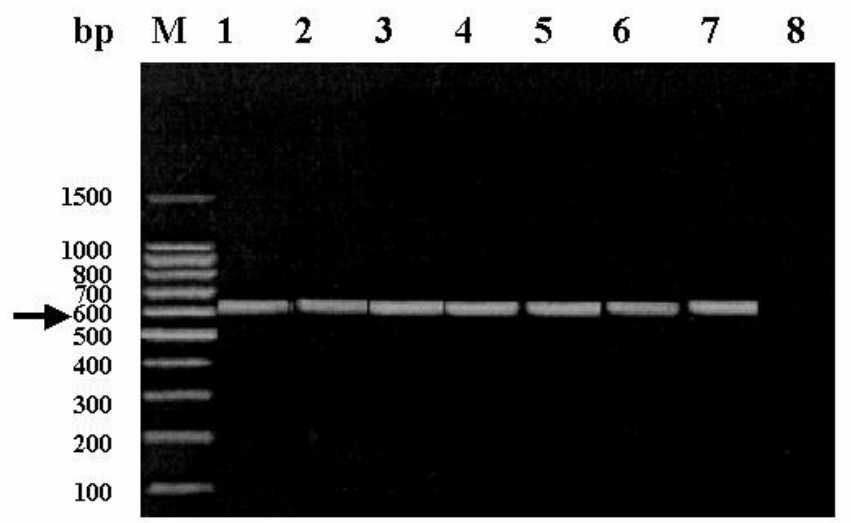

Lanes 1 to 7 are SA 1, SA 3, SA 6, SA 8, SA 11, SA 12, SA 20. Lane 8 is the negative control. $\mathrm{M}$ is the $100 \mathrm{bp}$ marker.

\section{Analysis of plasmid DNA}

Out of 17 isolates, 16 had plasmids of comparable size (14.2-15 kb), some of which are shown in Figure 4. Molecular weights were calculated by comparing Hind III digested $\lambda$-phage DNA marker and were analyzed by using Photocapt MV software.

\section{Methicillinase expression assay}

Spot inoculation test performed to detect the expression of methicillinase showed four isolates producing methicillinase, SA13, SA 14, SA19 and SA20.
Figure 4. Plasmid profile.

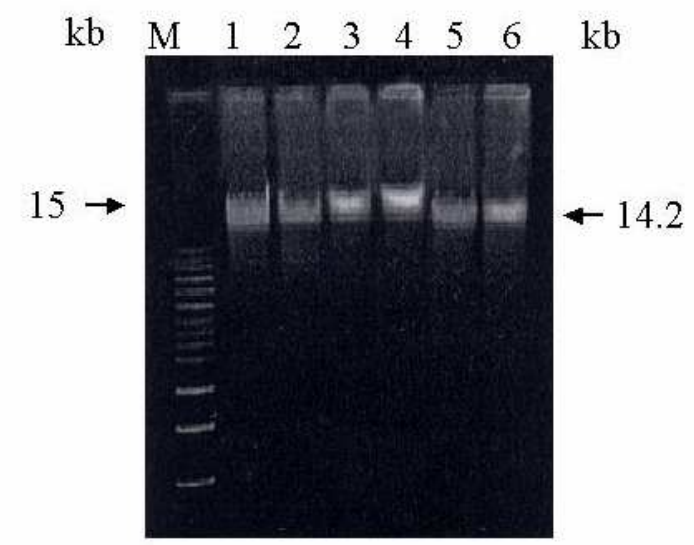

Lanes 1 to 4 are SA 14, SA 15, SA 19, and SA 19; their molecular weight is $15 \mathrm{~kb}$. Lanes 5-6 are SA 7 and SA 9; their molecular weight is 14.2 . M is $1 \mathrm{~kb}$ DNA ladder.

\section{Discussion}

Recent research has revealed that colonization of MRSA poses a substantial threat for the hospital environment, resulting in nosocomial infections. The word colonization here does not mean the normal sites of colonization (nostrils and in the skin of the axilla/groin.), but rather unhygienic surfaces, such as the hands of the hospital personnel. According to NNIS data for the year 2004, 59.5\% of $S$. aureus strains causing infections in hospitals were MRSA. This is not only true for Europe and United States but for India as well. Initially, occasional reports on MRSA were available, but now it has become one of the established nosocomial pathogens [29]. Although no surveillance system exists, the figures obtained from some large medical care facilities including tertiary care hospitals is alarming, with percentages as high as $51.6 \%$ to $54.8 \%$ [29,30]. This is much higher than the range of 20 to $32.8 \%$ shown by earlier reports $[31,32]$. Since our sample size is very limited, we can not represent the entire situation; however, at least in the premise of this hospital, our data has significance and it can be said that MRSA are emerging in the hospital environment.

Health care workers usually act as asymptomatic carriers of multiple drug resistance organisms, especially MRSA, and help in its transmission to patients [4]. This study was conducted using isolates from hand swab samples, keeping in mind the spread of MRSA in the hospital environment through the hospital personnel. 
Reports of patients with serious MRSA infections, who had no known risk factors or previous exposure to a health care setting, have been increasing [13-19]. .The analysis of the antibiotype of $S$. aureus clones isolated in this study showed resistance against different groups of antibiotics including $\beta$-lactams of second- and third-generation of cephalosporin. Of the 17 isolates, 5 showed multiple drug resistance. Moreover, a common feature shown by these strains is a high resistance against ceftriaxone. Three isolates (SA20, SA19 and SA14) showed resistance against multiple antibiotics (5 to 13 antibiotics), while the remaining ones were resistant to one or more antibiotics (Table 2). The only isolate susceptible to all the antibiotics used in the study was SA6. Furthermore, these strains were classified as different types based on their antibiogram (Table 2).

Plasmid profiling showed that these isolates (SA14, SA19 and SA20) had plasmids of similar molecular weights; however, their restriction fragment analysis revealed their diversification in band patterns (data not shown). This observation might be a result of these plasmids carrying different gene cassettes for resistance against different classes of antibiotics [33].

Although high methicillin resistance in isolates of $S$. aureus was not found in our study, its emerging profile $(18 \%$ exhibiting methicillin resistance) is a sign of danger for both community acquired and hospital-associated infections. Methicillin resistance is either due to expression of mecA gene or the synthesis of methicillinase or due to both. [34]. All the isolates were subjected to PCR amplification of mecA gene. PCR results revealed that seven isolates were carrying mecA gene. Of the mecA positive isolates, only SA20 was also found to be phenotypically resistant to methicillin. The remaining isolates did not show phenotypic resistance probably due to the overexpression of $m e c R$ and $m e c l$ genes which are corepressors of $m e c A$ gene $[35,36]$. Methicillin resistance (MR) shown by SA19 and SA14 is not a result of mecA expression. The expression of MR in these isolates was further studied by spot inoculation test to detect methicillinase. In addition to the above, SA13 and SA20 were also expressing methicillinase. Therefore, SA 20 might be showing a dual mechanism for resistance against methicillin, i.e. the expression of both PBP $2 \mathrm{a}$ and methicillinase.

The repression of $m e c A$ gene and the resulting absence of MR in some of the isolates could be due to several factors. Both genetic and environmental factors play a significant role in the expression of MR. The genetic factor could be repression of mecA by mecl and mecR1, which are its co-repressors [37]. The induction of $m e c A$ gene occurs through a signaling pathway initiated by the interaction of $\beta$-lactams with $\operatorname{mec} R 1$, a trans-membrane protein [38]. Therefore, selective pressure generated by indiscriminate use of antibiotic therapy is an important environmental factor in the induction of mecA gene [37].

The present study demonstrates the production of methicillinase in some of the MRSA strains isolated from hospital workers. It also suggests that $S$. aureus, suspected to be carriers of $\operatorname{mec} A$, should be the subject for both phenotypic and genotypic analysis to confirm their MR status. According to this study carried out in Chandigarh, the least effective antibiotics against MRSA are ceftriaxone, tobramycin, and penicillin, whereas the most effective ones are chloramphenicol, amikacin, and ciprofloxacin. It is highly recommended that hospital personnel dealing with patients should be trained for hand washing in order to help control nosocomial infections.

\section{Acknowledgement}

This work was supported by internal funds of the Biotechnology Unit, AMU, Minor Research project of UGC, D.no 4602. bt and CSIR grant no. 37(1209)/04/EMR-II to AUK

\section{References}

1. Goldmann DA et al. (1996) Strategies to prevent and control the emergence and spread of antimicrobialresistant microorganisms in hospitals: A challenge to hospital leadership. JAMA 275: 234-240.

2. Shales DM et al. (1997) Society for Healthcare Epidemiology of America and Infectious Diseases, Society of America joint committee on the prevention of the antimicrobial resistance: Guidelines for the prevention of antimicrobial resistance hospitals. Clin. Infect Dis 25: 584-599.

3. Centers for Disease Control and Prevention. (2003) National Nosocomial Infections Surveillance (NNIS) System Report: data summary from January 1992 through June 2003, issued August 2003. Am J Infect Control 31: 481-498.

4. Chambers HF (2001) The changing epidemiology of Staphylococcus aureus? Emerg Infect Dis 7: 178-182.

5. Warshawsky B et al. (2000) Hospital and community based surveillance of methicillin-resistant Staphylococcus 
aureus: previous hospitalization is the major risk factor. Infect Control Hosp Epidemiol 21: 724-727.

6. Salgado CD, Farr BM, Calfee D (2003) Communityacquired methicillin-resistant Staphylococcus aureus: a meta-analysis of prevalence and risk factors. Clin Infect Dis 36: 131-139.

7. Egeria, JM, Chambers H (2003) Community-acquired methicillin-resistant Staphylococcus aureus: epidemiology and potential virulence factors. Curr Infect Dis Rep 5: 459-466.

8. Naimi TS et al. (2000) Epidemiology and clonality of community-acquired methicillin-resistant Staphylococcus aureus in Minnesota, 1996-1998. Clin Infect Dis 33: 990996.

9. Embil J et al. (1994) Methicillin-resistant Staphylococcus aureus in tertiary care institutions on the Canadian prairies, 1990-1992. Infect Control Hosp Epidemiol 15: 646-651.

10. Turnridge JD, Bell JM (2000) Methicillin-resistant Staphylococcus aureus evolution in Australia over 35 years, Microb Drug Resist 6: 223-229.

11. Vandenesch $F$ et al. (2003) Community-acquired methicillin-resistant Staphylococcus aureus carrying Panton-Valentine leukocidine genes, worldwide emergence. Emerg. Infect Dis 9: 978-984.

12. Lowy FD (1998) Staphylococcus aureus infections. N Engl J Med 339: 520-532.

13. Centers for Disease Control and Prevention (2003) Methicillin-resistant Staphylococcus aureus infections among competitive sports participants- Colorado, Indiana, Pennsylvania, and Los Angeles County, 2000-2003. MMWR Morb Mortal Wkly Rep 52: 793-795.

14. Salmenlinna S, Lyytikainen O, Vuopio-Varkila J (2002) Community acquired methicillin-resistant Staphylococcus aureus. Finland Emerg Infect Dis 8: 602-607.

15. Gorak EJ, Yamada SM, Brown JD (1999) Community acquired methicillin-resistant Staphylococcus aureus in hospitalized adults and children without known risk factors. Clin Infect Dis 29: 797-800.

16. Groom AV et al. (2001) Community acquired methicillinresistant Staphylococcus aureus in a rural American Indian Community. JAMA 286: 1201-1205.

17. Naimi TS et al. (2003) Comparison of community and healthcare-associated methicillin-resistant Staphylococcus aureus infection. JAMA 290: 2976-2984.

18. 17. Baggett $\mathrm{HC}$ et al. (2003) An outbreak of communityonset methicillin-resistant Staphylococcus aureus skin infections in southwestern Alaska. Infect Control Hosp Epidemiol 24: 397-402.

19. Centers for Disease Control and Prevention (2004) Community-associated methicillin-resistant Staphylococcus aureus infections in Pacific IslandersHawaii, 2001-2003. MMWR Morb Mortal Wkly Rep 53: 767-770.

20. Eady EA, Cove JH (2003) Staphylococcal resistance revisited: community-acquired methicillin-resistant Staphylococcus aureus-an emerging problem for the management of the skin and soft tissue infections. Curr Opin Infect Dis 16: 103-124.

21. Collee JG, Fraser, AG, Marmion BP, Simmons A (Ed.) (1996) Mackie \& McCartney, Practical Medical Microbiology, 14th, Edition Churchill Livingston, New York.
22. Brakstad OG, Aasbakk K and Maeland JA (1992) Detection of Staphylococcus aureus by polymerase chain reaction amplification of the nuc gene. $J$ Clin Microbiology 30: 1654-1660.

23. Performance standards for antimicrobial susceptibility testing: sixteenth information supplement. CLSI document M100-S16 (ISBN 1-56238-588-7) Clinical Laboratory Standard Institute, 940 west Valley Road, Suite 1400, Pennsylvania 19087-1898 USA (2006) vol: 26 no.3.January 2006. Villanova, PA.

24. Birnboim HC, Doly J (1979) A rapid alkaline extraction procedure for screening recombinant plasmid DNA. Nucleic Acids Res 7: 1513-1523.

25. Ish-Horowicz D, Burke J F (1981) Rapid and efficient cosmid cloning. Nucleic Acids Res 9: 2989-2998.

26. Boom R, Sol CJA, Salimans MMM, Jansen CL, Wertheim-van Dillen PM E and van der Noordaa J (1990) Rapid and simple method for purification of nucleic acid. Journal of Clinical Microbiology 28: 495-503.

27. Prasad KN, Kumar R, Tiwari DP, Mishra KK, Ayyagari A (2000) Comparison of various conventional methods with a polymerase chain reaction assay for detecting methicillin-resistant \& susceptible Staphylococcus aureous starins. Indian Journal Med Res 112: 198-202.

28. Shahid M, Malik A, Agrawal M, Singhal S (2004) Phenotypic detection of extended-spectrum and Amp-C beta-lactamases by a new spot-inoculation method and modified three-dimensional extract test: comparison with the conventional three-dimensional extract test. J Antimicrob Chemother 54: 684-687.

29. Mehndiratta PL, Vidhani S, Mathur MD (2001) A study on Staphylococcus aureus strains submitted to a reference laboratory. Indian J Med Res 114: 90-94.

30. Anapurba S, Sen MR., (2003) Prevalence of methicillin resistant Staphylococcus aureus in a tertiary referral hospital in eastern Uttar Pradesh. Ind $\mathrm{J}$ Med Micro 21: 49-51.

31. Mehata AP, Roderigue C., (1998) Control of methicillin resistant Staphylococcus aureus in a tertiary care center: a five-year study. Ind J Med Microbiol 16: 31-34.

32. Shankar CU, Harish BN, Kumar PMU, Navaneeth BV, C Udaya Shankar, P M Umesh (1997) Prevalence of methicillin resistant Staphylococcus aureus in JIPMER Hospital - a preliminary report. Ind J Med Microbiol 15: 137-141.

33. Khan AU, Musharaf A (2004) Plasmid-mediated multiple antibiotic resistance in Proteus mirabilis isolated from patients with urinary tract infection. Med Sci Monitor 10: 598-602.

34. Dominguez E, Zarazaga M and Torres C (2002) Antibiotic resistance in Staphylococcus isolates obtained from fecal samples of healthy children. J Clin Microbiol 40: 26382641.

35. Lewis R A, and Dyke KG (2000) Mecl represses synthesis from the beta-lactamase operon of Staphylococcus aureus. J Antimicrob Chemother 45: 139-144.

36. Lowy FD (2003) Antimicrobial resistance: the example of Staphylococcus aureus. J Clin Invest 111: 1265-1273.

37. Kolbert CP et al. (1998) Branched-DNA Assay for Detection of the mecA Gene in Oxacillin-Resistant and Oxacillin-Sensitive Staphylococci. J Clin Microbiol 36: 2640-2644. 
38. Zhang $\mathrm{HZ}$, Hackbarth $\mathrm{C}$ J, Chansky KM, and Chambers HF (2001) A proteolytic Transmembrane Signaling Pathway and Resistance to beta-lactam. Science 291: 1962-1965.

Corresponding Author: Asad Ullah Khan, Interdisciplinary Biotechnology Unit, Aligarh Muslim University Aligarh 202002 India, Phone: 0091-571-
2720388 Fax: 2721776 Email: asad.k@rediffmail.com, huzzi99@hotmail.com.

Conflict of interests: No conflict of interest is declared. 